\title{
The Concept of Therapy in Ancient Greek Texts \& Dance Practices
}

\section{Lazou A*}

School of Philosophy, University Campus of Zografou, Greece

*Corresponding author: Anna Lazou, School of Philosophy, University Campus of Zografou, 15703, Athens, Greece, Tel: 2107277503; Fax: 210 7248979; Email:lazou2011.ancientorchesis@ gmail.com

\section{Conceptual Paper}

Volume 4 Issue 3

Received Date: June 28, 2021

Published Date: August 02, 2021

DOI: $10.23880 /$ abca-16000189

\section{Abstract}

In the context of the research effort of the Ancient Orchesis Study Group to reconstitute the philosophical and wider cultural presuppositions that define the ancient Greek dance culture, from which the Greek-speaking and Roman world was removed, to return with the Renaissance in a new European context, along with the recognition of the basic anthropological, on the one hand, aesthetic, on the other hand, criteria and principles of art and, in particular, of dance expression, we attempt a review of

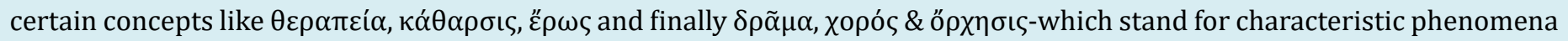
of ancient Greek culture. This article plays the role of an introduction into the philosophical-historical investigation and understanding of concepts of intrinsic importance in the question about relating philosophy with art and therapy in the ancient world.

Keywords: Therapy; Orchesis; Embodiment; Poetry; Drama; Dance; Catharsis; Interdiscipli Narity; Education; Ancient Greek Culture; Eros; Persians; Eumenides; Aeschylus; Sophocles

\section{Towards an Interdisciplinary Approach of Ancient Greek Culture}

In the beginning of human civilization, art and philosophy were incorporated in the established efforts of therapy \& healing of the suffering man. This practically meant that the 'therapist' of the community or tribe used all mental and physical skills available in combination with every art form that was available (music, painting and dance in particular), with its unique intention to 'cure'. Later, with the progress and increase of knowledge in human societies, these branches were separated. Philosophy became mainly a logical search of truth through concepts, art became autonomous with the main goal of aesthetic pleasure and the healing practices became medicine. We reached the $21^{\text {st }}$ century AD, to 'rediscover' and state once more the ancient bonds that unite philosophy, art and healing. So, for example, now there are psychoanalytic methods in use of the creative writing aiming at a psychological kind of therapy, there are also plays conveying philosophical ideas, which they implement on stage (let us remember here Sartre e.g.), but there are also trends in the medical community who talk about the need for a more 'holistic' approach to therapy, beyond the strict confines of biochemistry and pharmaceutical medicine. Given our intention to contribute fruitfully and authentically to a more effective approach of the links between philosophy, art and healing (therapy), all of us who have contributed to this journal with our research, as members of the same research community, we strive to bring to the fore the promising 'wholeness' and reconsider the object of our research with a fresh and authentic look.

In my opinion, the constant and uninterrupted history of the interest for the understanding, interpretation and knowledge of all the elements that illuminate the values and deeds of ancient Greek culture can be explained by the perspective of its physicality, the uses and functions of the 
human body in relation to them. Studying and understanding this perspective is not limited to access to the literary sources of ancient writers, even in a wide historical spectrum, but also involves other sciences and methods, which will be briefly presented as an attempt to found a systematic methodological approach in this area of research [1].

In this regard, one of the essential tools for the philosophical understanding of the subject, I consider to be provided by the interdisciplinary or interpretive archaeological research that focuses on how the art of depicting the body conveys or translates structures and functions of human society and the era that produces these artistic forms. The method of interpretive archaeology (IA) e.g. uses concepts produced by power relations and by the ways that culture incorporates human activity (agency) and tangible experience. In contrast to the semantic and linguistic expression of kinetic systems as relations of bodies in space and by reference to wider environments -abstract systems of continuously changing relations, I $A$ provides physicality with the historical depth and perspective of changes in social life forms, but at the same time watching the solid or static object of the image, that is preserved as it is, even worn or broken in the excavation soil. We will then see an application of this interpretive approach to ancient or -even- lost dance descriptions, with the example of one of the many monuments depicting dance, the famous Oinochoi of Dipylos. To return to the methods of Interpretive Archaeology that considers images and objects as supposed vehicles of description - 'translation' of authentic realities, and how it is applied in the case of the understanding of the Oinochoi of Dipylos, the interest is transferred from the epigraphic text to the construction of Oinochoi itself, in its very shape and image. The working hypothesis here is that in earlier historical eras where these works were produced, there were simultaneously changing perceptions and practices of the body associated with the changing forms of life blossoms or 'life worlds'. In a thorough approach of the archaic Corinthian angiography by Shanks M, et al. [2], the work of the archaeologist is presented as a description of different techniques of depicting the bodily self, at that time, which should be explicitly correlated with the ideological structure underneath the dominant technology of power therefore. This technology of power is always alive in human societies as a struggle with violence, barbarism, threatening alienation or inferiority and social exclusion, according to interpretations of anthropologists such as Jean-Pierre Vernant and René Girard and thinkers such as Gilles Deleuze and Félix Guattari, Michel Foucault, etc.; relevant explanations float on an inaccessible ocean of movements and actions of the human bodies, but also animals, as well as gods and monsters. While the complexity of the meanings of the movements remains as high as the complexity of the language codes, it is the power of the object, the material rescued product, that allows the world of agents to survive through time and conveys valuable information of their expressive aesthetic values to the present. We attempt a theoretical approach of these concepts as representative but also as phenomena characteristic of the ancient Greek dancing and therapeutic culture.

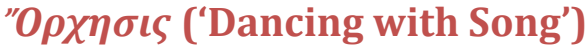

What is orchesis and why is it important for the study of the ancient Greek drama? Human dancing, which, in ancient Greece represented every kind of movement of the feet, hands, head or even the eyes, did not constitute a selfcontained art. It was combined with music and the recitation of lyrics, even with an individual or a collective dramatic action. Literature and more specifically, poetry, was tightly linked with music and dance, from the earliest eras of its existence. Greek poetry's evolution was very much influenced by the appearance of dance -as the use of the word toús, which means foot, indicates, among other elements, a part or a metrical unit of a verse. Regarding to this, a fragment of Libanius, a Greek teacher of rhetoric of the Sophistic school, is frequently cited: "Dancing is not made complete by songs, rather it is for the sake of dancing that the songs are worked out". Recent research about op $\rho \chi \sigma$ เৎ focuses on the poetic as well as on the philosophical texts of antiquity but also taking into accounts more principles and criteria of the interdisciplinary investigations, such as

- Religious and cult rituals and myths,

- Various dance practical skills and dexterities,

- Aesthetic excellence,

- Social, educational and therapeutic functions of body and dance practices,

- Self-knowledge and personal development and

- The philosophical interpretation of human dancing activity and other theoretical presuppositions. As the working hypothesis of this research approach is to be taken the significance of the organic unity of three



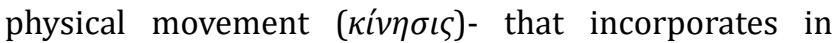
rhythmic forms of spoken word the primary identity of these three aspects appearing in the ancient Greek civilization that is expressed both in the forms and the way of life (athletics, education, politics, medicine, everyday life), as well as in specific artistic creations (theatre, sculptures, paintings and poetry). Secondarily, philosophical thought emerges to seal the summit and unprecedented three dimensional identity of ancient Greek art and culture. The multidimensionality and interdisciplinary of the orchesis research may be paradigmatically illustrated by the investigation of $\varepsilon \rho \omega \varsigma$ as a concept in ancient literature and a cultural phenomenon (Figure 1). 


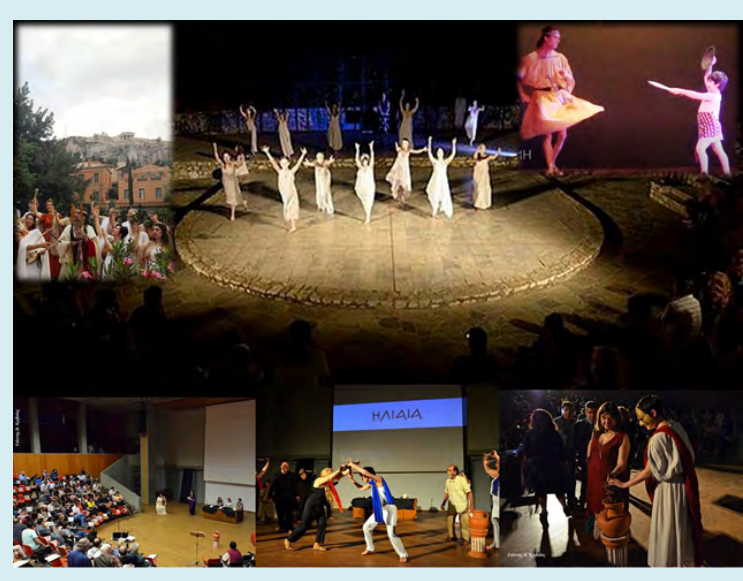

Figure 1: Photos of Orchesis Study Group \& Dryos Topoi Research \& Artistic Ensemble Activities.

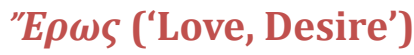

Our focus on the theme of $\varepsilon \rho \omega \varsigma$ is due to its uniqueness, variety and multidimensional use in almost all aspects and expressions of the ancient Greek cultural structure, but also to its timeless dominance through its transformations in almost all historical periods until today. "E $\rho \omega \varsigma$ is referred to by the tragic poets as a wise entity or being, but also as a natural force inherent in every living creature, that continues and explains its attractive relationship with other beings of the world. On the basis of this main axis of meaning of the concept, the relationships in which love engenders beings and especially human beings, acquire many different qualities and particularities that enrich the content of a complex and largely realistic psychology of the myths that the dramas of tragic poetry deal with. As well as a series of concepts describing or interpreting human functions and situations of life (friendship, war, state, education, etc.) " $\rho^{\prime} \rho \omega \varsigma$ too occupies a wide range of texts and interests of the corpus of the ancient Greek literature, presenting both a philosophical, as well as a cosmological and psychological thematic scope.

If we were to draw a general conclusion as to how dramatic poetry approaches the issue of $\varepsilon \rho \omega \varsigma$, before we see the corresponding subject in epic and lyrical poetry, or in the platonic dialogues, we could reasonably formulate the view that $\varepsilon \rho \omega \varsigma$ in our three tragic poets is a popular theme, both as a constitutive force of the mythical plot, as well as an anthropomorphic deity explaining the human sufferings being dealt with. In the famous stasimon of Sophocles' Antigone, which can be compared to similar thematic choruses of Medea and Hippolytus by Euripides, there is a climax of gloomy and negative forces with which tragic poetry connected $\varepsilon \rho \omega \varsigma$. It is a factor of eras, tribulations and misfortunes, as dominant in both the realms of immortal gods and mortal men.
A common place among the poets traditional or artfulconcerns the fragility of the victims of love, as victims of an unpredictable and irresistible attack, while the poetic icons are complemented by numerous illustrations of similar issues in vases and sculpture. Ethics of sexuality is a central theme within the Greek thought at least concerning the free males- as a form of relationship expressing the exercise of the individual's freedom of power and as an access to truth. The access to truth is characteristic of human nature and is revealed through man's relationship with the other human beings and thus the realization of man's ability to discover and preserve the connection between $\varepsilon^{\prime} \rho \omega \varsigma$ and truth. In philosophical literature $\varepsilon^{\prime \prime} \rho \varsigma$ is identified as the power that tends to integrate and attain immortality. As a primary attraction, it is a force capable of classifying and giving life to everything. It forms different steps, from a fine sky to a tangible land, on each level there being a different form of love. And to get to the essence of love, we must learn how to climb a ladder starting from beauty; beauty existing in the bodies, souls, in actions, and the laws of nature, in science and in art, and further on we reach the beautiful as a pure idea, in the abstract form of beauty, fine and flawless, but which

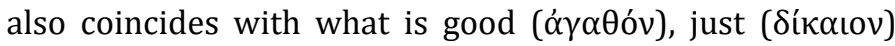
and truth itself ( $\alpha \lambda \eta \theta \dot{\varepsilon} \varsigma$ ). Claude Calame furthermore makes a systematic inquiry into the sexuality of ancient Greeks and attempts to outline the physiognomy of the power that the Greeks deified with the name $\tilde{\varepsilon} \rho \omega \varsigma$. He starts from the physiology of love, he then studies literary expressions and artistic depictions, and goes on to examine the institutions that support love, as well as the places where $\tilde{\varepsilon} \rho \omega \varsigma$ exercises its power. The glorification of love, however, does not only mean depicting love affection but also exploring it by means of the concept of social practice. Poetry and iconography motivate their recipients to reflect on the functionality of eros by means of the institutions of the city.

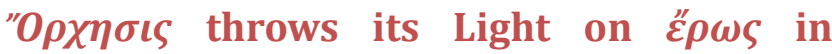 Sophocles' Antigone}

The third stasimon of the third episode of Sophocles' Antigone, following the dialogue between Creon and Haimon, praises love, the driving force in everything, in the tragic context of the opposition between the institutional law (customs and traditions) and the laws of the city. This vicarious anthem begins with a definition of love. Initially, the predominant concept, $\tilde{\varepsilon} \rho \omega \varsigma$, is presented and then it is analyzed. The choral system chosen by the poet is strophe and antistrophe. In the strophe, love emerges as a creative force for life (verse 781-790), while the antistrophe is related to the plot itself, so, there is an evolution from the general to the particular. In fact, the features of the personified winged deity are outlined and its omnipotence and dominance in the terrestrial and heavenly world are emphasized. The extent of ' $\varepsilon \omega \varsigma$ ' dominance coincides with the intensity in 
which $\varepsilon \rho \omega \varsigma^{\prime}$ acts are expressed through verbs indicating

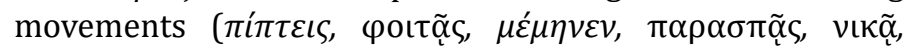

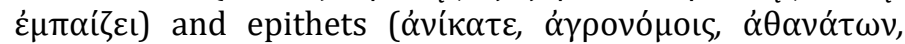

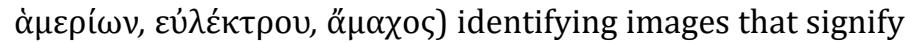
the irresistible nature of love. The ode starts with the word $\varepsilon \rho \omega \varsigma$, which is repeated in the same position of the next verse and ends with the invocation of the name of Aphrodite ( $\theta \varepsilon$ cos 'A $\varphi \rho о \delta i ́ \tau)$. The chorus attributes the characteristics of the personified deity:

- It is invincible in the battle, therefore all powerful,

- 'Fills' the creation with its momentum,

- Overnights on the tender cheeks of the maidens,

- Travels' around in the sea and in the fields,

- Captures without distinction mortals and immortals,

- Fools anyone who gets caught by $\varepsilon ̋ \omega \varsigma$.

The culmination of ' $\varepsilon \omega \varsigma^{\prime}$ essence, i.e. madness to which $\varepsilon^{\prime \prime} \rho \omega \varsigma$ ( $\delta^{\prime} \varepsilon^{\prime \prime} \chi \omega \nu \mu \varepsilon \dot{\mu} \mu \eta \varepsilon v$ ) leads to, has as a reasonable consequence the antistrophe, that follows. In particular, it is emphasized that:

- $\quad \varepsilon \rho \omega \varsigma$ 'vanquishes' ( $\varphi \rho \varepsilon \dot{v} \alpha \varsigma \pi \alpha \rho \alpha \sigma \pi \tilde{\alpha} \varsigma$ ) the mind of the righteous,

- Has brought the dispute (vยז̃ко) between father and son to the royal family, $\gamma$ )

'The desire on the eyelids of the beautiful bride'

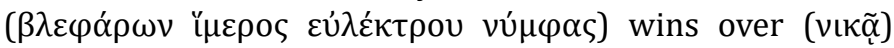
and love presiding together with the major institutions

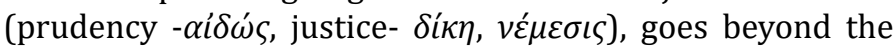
power of the natural and moral laws that regulate the order of universe. "E $\rho \omega s$, under the auspices of the playful goddess Aphrodite, has a superhuman impact and an irresistible power. Following the escalation of the determinations of its essence, $\tilde{\varepsilon} \rho \omega \varsigma$ moves to a transition from tenderness and lightness to cruelty and reverence. Love leads to madness, surpassing the power of natural and moral laws, having a catastrophic impact. It is even mentioned in the desperate father-son confrontation and in the erotic madness inspired by Aphrodite. With a unique stability in the use of verbal terms and references, one might claim, this chant retains its inwardness and depth of philosophical meaning, while dancing with a rhythmical series of steps and gestures that indicate this content, follows as a logical consequence of the very idea of its poetic structure and the actual meaning of the words. Investigating the way of life, the texts and sculptures of the ancient Greeks, we realize that it is inconceivable to interpret dramas and tragic poetry leaving aside expressive movements or some kind of bodily expression but with a static engagement of speech only. Having solely read the text, we feel the vibrations that are reproduced by it and lead to the undisputed conclusion that the chorus is moving and even dancing as there is no other way to express these concepts. Thus, we conclude that the essence of its meaning lies in the somatization of speech, by 'dancing' and 'singing' the words and syllables. Through the reconstruction of a bodily meaningful whole consisting of steps and gestures, while being a kind of dance that belongs to the contemporary era, specifies and illuminates at the same time the actual functions of dancing and chanting as a diachronically meaningful human activity with both therapeutic applications and artistic values (combining beauty with creativity). But this effort is mainly and basically interdisciplinary, it is a way of connecting or 'translating' theory into practice and vice versa, or even 'reading' with the body, and its language those procedures and forms of understanding that concern the mind and its conscious elaborations of reality. What is important in this experiment of revival is to learn how to connect and critically reconsider the established knowledge of the past and expressing this new conjunction with a beautiful series of meaningful movements. As archaic painters insist on the repeatability and order of the depicted, imposing an organic regularity on the forms, their society also insisted on the emergence of structured, subtle actions, thus imposing a steady group of correlations that encapsulate and inactivate conflicts and threatening contrasts. A similar tactic of opposing forces can be seen in the structure of ancient choruses as metrical poetic rhythmical forms. If today, for example, we want to represent one of these choruses, we must move from the 'body' of the text to the 'body' of concepts and the human subjects that inspired or created them; ultimately, of course, to the systems of these subjects' relations. In our own tangible representation we will set the boundaries and rules of new relationships and interpretations that concern us. By reference -among many examples- to the sociological interpretation of a subject, such as the erotic behavior of a past civilization, a theme that literally involves the 'ancient body', I try to show the multidisciplinary and interdisciplinary nature of the study, from which valuable information can be obtained allowing for a comprehensive training on the issues involving the human body with its physicality and beyond the textual philological -historical- linguistic approach. In addition, how poetry and vase representations or sculpture depicted the human body, alongside with how the philosophical reflection spoke of it, contribute to one thing: to provide valuable material to the socio-historical understanding of the meaning and use of the body. The visual images of the depicted bodies refer to relationships and imply moral, political relations -sociology insists on relations of power and the dynamic imposition of a system of relations on another: complexes of actions and tools, choices and technical possibilities, personal motives and environments- frameworks, concepts and perceptions of the self and the body, which are therefore suited to the indicated interests and objectives. 


\section{Interdisciplinary Research and the Cooperative Practices of Art \& Philosophy}

At this point I would like to refer in an introductory way to certain theoretical presuppositions supporting those collective efforts in the area of arts and humanities that I propose with my approach.

We suppose that in the various instances of cooperative relationships that compose the web of such social designs, as in the artist-creation relationship, therapist and patient or philosopher and student etc., there is a specific connection of normative or ethical parameters that can be diagnosed and which determine the special quality and psychological content to these [3]. According to such a point of view the common characteristics allowing for a methodological convergence of these areas derive from their cooperative and dialectical nature. Recent literature following this line of approach also shows the influence of socio psychology of Lev Vygotsky in theater in education [4], while it's most specific therapeutic model is the theater of the oppressed by Boal A, et al. [5]. Literally, in The Psychology of Art and during his early phase of the exploration of consciousness under a culturalhistorical perspective characterized now as yet unexplored though-Vygotsky attempts to reconcile the Marxist approach to the human being with recent behavioral trends in the Soviet scientific psychology [6]. Similar applications deriving from these theories can be seen in the field of children education [7].

In the philosophical-psychological premises of these studies we find a non-Cartesian explication of the self, which attributes particular priority to the human subject, socially self-identified and places the tangible existence of people at the center of events and phenomena under investigation. Such theories (in which we compile the literary criticism of Mikhail Bakhtin, the anthropolinguistics of George Lakoff and Mark Johnson and Antonio Damasio's Neuroscience) focus on the relation between mind and language and develop through socio-psychology the idea of the collective identity of the self. Concluding this introductory note, within the limits of my article, we owe a special mention of Ludwig Wittgenstein, as the philosopher who, although belonging to the tradition of analytical thought, distances himself from the philosophy that attempts to extract the meaning of words from the logical context of propositions and, on the contrary, considers the meaning of a word as revealed through the explanation or description of the way in which the word operates and is performed within a language game, that is, in the social context of an act and its appropriate rules.

Moreover I would like to point to the interdisciplinary and holistic approach as necessary for the understanding of concepts like catharsis, mimesis, orchesis and drama as well as their function. According to Andy Blunden, the unified concept of human activity (Activity/Tätigkeit), arising from the combination of Hegelian social philosophy, the marxist analysis of social phenomena and Vygotsky/Leontiev's social psychology allows the application of an interdisciplinary field of research and explanation of all cultural products art [8], science and philosophy, all theoretical-practical forms of expression, outside the hermeneutic vicious circle. Vygotsky, in Blunden's outlook, believes and emphasizes that concepts of everyday language and communication can be true because they represent different institutions of the social structure -art, religion, economics, politics, science, philosophy- demonstrating the intersection of different and multiple universalities of understanding, in the experience of life [9]. The concept of understanding, as used here, is to be considered as different from the hermeneutic cyclicality, when in fact the interpreter-reader encounters texts of different historical origin or different cultural traditions, although, for Blunden, and for us, the essence of understanding lies in the relation of the elements to each other, in their sharing of a common meaning.

I believe that the above constitute a systematic theoretical premise guiding our study of how to approach concepts like catharsis, orchesis and drama and relevant phenomena of ancient art and therapeutic practices. More particularly these concepts are to be connected with their social and historical background in parallel with their philological and textual appearance, in order to be fully illustrated and successfully used in artistic, educational and/or therapeutic expeditions.

\section{Experiential Examples}

I am going to list moments or situations out of my personal experience, where art and philosophy were interacting in order to illustrate their impact in educational practice with emphasis on the therapeutic key role of their combinatory presence. These experiences may be classified according to two different ways -or paths- that art and philosophy can be interconnected:

- The first path -how to understand and approach art through philosophy, along with other issues vital to human life, has become a popular and widespread issue in the history of ideas and recent aesthetics. The timeless interests of philosophy to define art and some related phenomena of the human culture prove the practicality and applicability of philosophy through art - and specifically the art of theater - in everyday life [10].

- The reverse path -how to enrich, shape or transform philosophy through art, whether investigation of the classical philosophical questions can be illuminated and even transformed by applying art in teaching, is a recent and still open question for examination. In this respect our examples constitute a rather original experiential material, on the basis of which our theoretical 
documentation attempts to establish conditions of systematic negotiation.

\section{Aeschylus' Persians}

As a starting point of my practical experimentation and reflection on art, philosophy and therapy, I consider Aeschylus's Persians, a performance by Gementzakis M, et al. and a Symposium at the University of Gävle, in Sweden, when I presented for the first time the discussion about the so-called body-mind problem and tried to recognize in the actor's relationship with the body a model for solving the well-known philosophical problem. Then, I was given the opportunity to study the relevant presocratic notions

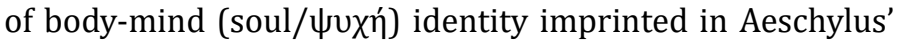
poetry and thus connect the dramatic figure of Xerxes, as the example -from the field of drama- nevertheless, of the inseparable bodily-mental unity, which is justified by the theatrical depiction of the hero's mental illness by Aeschylus' poetic metaphors; I later analyzed further the hypothesis of considering the actor on stage as a paradigmatic instance of human nature as an integral whole, in opposition to the newer positivistic divisive approach [11].

In our example, of the stage action of the tragic actor, we find with him ideally, the material for such findings: If the psychological states, our linguistic structures describing as mental events (mental attitudes or intentional states) 'resist' the explanatory power of the language of natural science (naturalized epistemology) and whether the modern conceptual schemes adopted by the actor and the spectator necessarily presuppose the use of a natural language and the physical scenery practice, then only with reference to natural facts and terms can the actor understand and represent the mental state of the tragic hero.

The actor who is expected to incorporate the dramatic persona of Xerxes in Aeschylus' Persians (normally a male actor), attempts to understand the text, the instructions and perceptions of the director, transform these perceptions into an action understandable respectively to the audience. The actor is worried about 'how to play' Xerxes and his psychic disease, observes the way that the poet describes the behavior and supposed mental state of the dramatic -at the same time- historical personality.

In the process of working with the text, one perceives

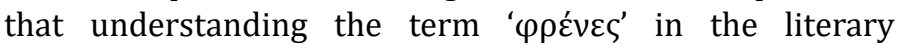
context of its use alone is not enough for the theatrical act of representing a mad hero, as Xerxes appears in the play; further reference to specific facts and events is required that concern neurophysiology and physical anatomy, the actual physical structure of the human body that is the actor's tool of artistic representation.

The use of the term ' $\varphi \rho \varepsilon \varepsilon^{\prime} \varsigma^{\prime}$ and the homonymous as well as synonymous words and phrases in the text of the Persians indicate moreover the metaphorical denotation of mental states and specifically the mental pain and passion of the hero in relation to particular physical events and body metaphors:

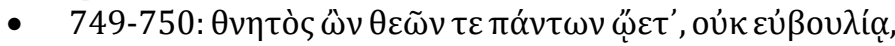

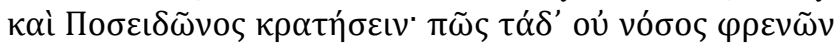

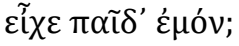

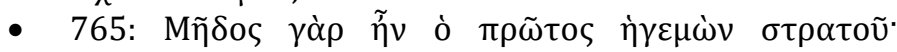

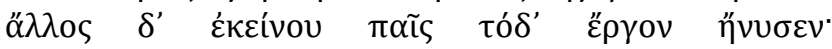

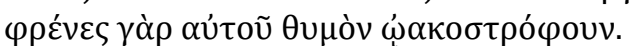

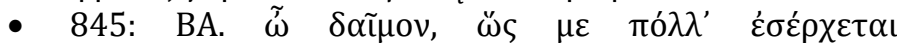

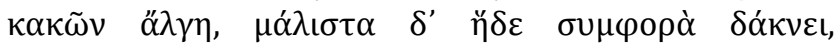

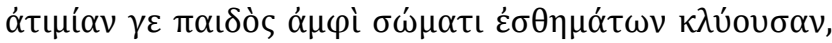

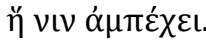

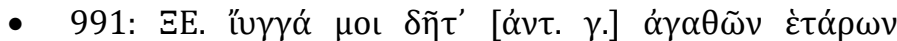

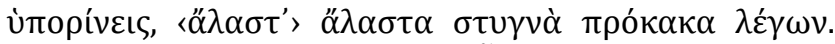

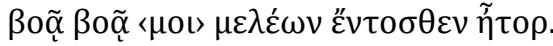

The literary analysis and interpretation of the theatrical text 'feeds' the actor with certain tools for a deeper understanding of the material related to the role. The focus is on working with the terms appearing in the text and the variant meanings that indicate different 'ways' of understanding the intentions of the poet in relation to the historical data of certain linguistic uses of the time period that the text had been created.

Dealing with language descriptions as well as working out how to render with the physical/bodily acts, at the same time the actor deals with various conceptual forms (the actor's, the director's, the poet's, the spectator's, the scientist's, etc.); as to how f.e. to understand, describe and finally represent -rather than imitate- Xerxes' 'mental illness' ('vóбos $\varphi \rho \varepsilon v \tilde{\omega} \nu$ ') in a persuasive way on stage [11].

\section{Eumenides}

The second example of the therapeutic uses of drama refers to Aeschylus' Eumenides on the occasion of my participation to the stage production of this drama by the Orchesis Study Group of Dora Stratou Theatre, in Athens, in 2012-13. In tragedy, 'therapy' as the restoration of the disturbed balance with a consequent painful process of purification takes place first within the limits of family relations and then extends to the limits of the city. In order to understand further the political message of this specific Aeschylus' tragedy, we should start from investigating the house-city relationship it narrates. This therapeutic -in the above sense- process is remodeled in an exemplary way in 
Eumenides.

If, following the literature on the subject, we assume that Oresteia is a political project that historically coincides with the emergence of cities as a result of previous struggles mainly about -among others- the issue of justice, then a reasonable conclusion would be that the moral-philosophical ideas and the conflicts among the human persons, they imply, are presupposed and have explanatory significance as to the actions of the heroes and their choices in the mythical plot. These are the deepest ideas that constitute the truth about human reality that are channeled through the poetic text, into the action of the heroes, but above all into the masterful operation of the 12-member group of Aeschylus' chorus. The chorus represents thoughts and feelings, conveying knowledge and information and mediating between the 'world' of the people attending (audience of the citizens) and the 'world' of myth and heroes (the actors and dancers in the orchestra).

Eumenides is a drama of transformation; we may recognize in the fear caused by Erinyes to Orestes, and then in the transgressors of the primordial institutions of law, a trick aimed at reaching a consensus between rival forces that appear as adversaries in a court founded and organized by a deity, Athena. It is the reconciliation between adversary powers in society that finally balance and cure the tragic pathos of revenge and violence. Throughout the evolution of the tragic myth, with the aim of purification at the end, it is revealed how the good, light and balance derive from the profane, impure and terrible. Thus, from this transformation that takes place in the context of the Eumenides, it is knowledge and truth being produced by a process of dark rivalry.

What should be further emphasized in relation to the therapeutic and educational functional role of drama especially in the case of Eumenides, is the priority of the system, the whole (laws, choral group actions, institutions and traditions, the city), over the individual act or the individual character. The grid or flow of events, according to which the actions of the hero (Orestes), trying to bring about a dramatic situation in consistence with the tragic ethos and poetic intellect, in order to test their correctness and efficiency, develop here with the purpose of highlighting the moral lesson coming out of the disastrous consequences of human mistakes. In Eumenides this grid is not composed of the actions and commands of gods (Apollo-Athena), who intervene occasionally in the plot, but from the dominant throughout the play action of the chorus -as Erinyes being transformed to Eumenides- while the main hero, Orestes, is finally forced to accept as inevitable the logic of tragic ethos, rationalizing the irrational, understanding the supernatural and ultimately paying the price with his own body, pain and punishment.

\section{Conclusions about the Therapeutic Uses of the Tragic Chorus \& Dramatic pilot in Aescylus' Persians \& Eumenides}

In archaic Greece, where Aeschylus was born, everything that is at stake about people's lives is closely linked to the demand for the moral unity that the institution of the family and the solidarity and interdependence of its members ensure. Hence the idea of hereditary guilt and transferable punishment, a common feature of early civilizations, composes the context of actions and poetic compositions of both dramas. Thus we see evil starting from the act of the ancestors darkening the mind of the son and their grandsons. The vengeful spirit leads the victim to the criminal act. Even the evil spirit of the house, Alastor, contributes to this. The afterlife for the soul, however, which was imagined by the theologians and the interest in the fate of the dead after death are not found in his works. For Aeschylus everything is fulfilled in this world.

There is faith in justice and the power of soul, as well as in the world of demons and their action. These are the forces of evil that act at all times and influence the judgment and actions of man. Surely Aeschylus is difficult to convince us that he reconciles the guilt of the perpetrator with the imposition of his unjust act by a higher power. On the one hand he accepted the action of the demons and on the other in his choruses he interprets the world of his heroes in a higher way, invoking the existence of a rational justice, a harsh moral law represented by the action of gods. Certainly in his time a progress was made. Arbitrary divine powers were replaced by the idea of secular justice, but this was linked to the existing primitive conception of the family and thus a new social ethic was not yet established. Only later, under the influence of Greek rationalism, did the weight of religious sentiment diminish and the religious law change, giving the individual the opportunity for personal responsibility and rights.

Aeschylus therefore lived in the world of faith in the demons, but tried to give them a higher interpretation as we see in Eumenides and to show through Athena how the world can be transformed into a new world of rational justice. The other two poets, Sophocles and Euripides, being 'children' of another era, challenged the existence of older beliefs through logical and moral arguments. Ancient family conflicts that constitute -more or less- the ground of the transformative procedure from hybris to rehabilitation, liberation and therapy of the hero standing among the gods and the chorus (as the collective action of the many) in Aeschylus' dramas, become less important than the rights of the individual 
and the independent of the family circle circumstances, for both Sophocles and Euripides. The heroes of Aeschylus are guilty of a primordial crime (Xerxes, Orestes) but many of Sophocles and Euripides' heroes (Antigone, Oedipus, Alcestis or Hippolytus) are genuinely innocent and their misery is brought to them by divine plans or by their enemies in society. The Aeschylian setting of the transformation is more drastically 'therapeutic', placing mental disease or revengeful passion at the center of the procedure. It is not about a rational choice in moral action that saves or liberates the hero's soul which would show a direct influence of the philosophical doctrines that later dominated but poetry itself with its spiritual activity and imitative power to cure the wounded consciousness of the hero, that prevails in Aeschylus, in contrast to the rationality of the next centuries with the subsequent degradation of the great drama. Religion and cult practices invoking those traditional myths known and perhaps unpredictably established in popular consciousness with a high pedagogical role embedded in them and had only to be transformed into Aeschylus' dramatic techniques with a unique indeed poetic skill so that would help people connect the old with the newer perceptions and to some extent reconcile it. The 'newer' beliefs concerned philosophical inquiry as the cornerstone of the interpretive approach to life and were manifested in the Platonic world affecting the evolution of theatre somehow dissolving its older therapeutic functions.

Aeschylus' dramas introduce on the hand, a strong relationship between justice and medical healing; this allows us to recall the relevant medical metaphors of Aristotle in the discussion of problems of politics and ethics, as to music and theatre (tragedy). Mainly based on the Aristotelian notions of equality, freedom and justice, measure or mediation, we may start understanding the very notion of therapy as an ongoing process of balancing and restoring the social and physical conflicts of individuals and social groups [12].

\section{Further Therapeutic Applications of the Dancing Revival of Antiquity}

Which is therefore the core of the therapeutic function of tragedy and Greek drama according to modern philosophical approaches and theories?. Our work hypothesis directs us to the investigation of dance as a constitutive element of Greek drama and wider cultural heritage. Apollonian rationality and Dionysian ecstasis as aspects of the same primordial human condition function in a complementary way by the alternation of order and discipline with expressiveness and ecstatic freedom. Indeed, in dance, man acts both as a unit and as part of a collective entity, despite the pain and suffering involved in the effort of integration of the opposed aspects -partial / totality- which means nothing else but the pain of life. Only in dance can one seek solace for this conflict situation. The role and functions of dance -in the chorus schemata are representative examples of the 'healing' process of the tragic drama.

Dionysian elements of dance-more particularly- are therapeutic both because of the psychological and its biological functions and influences, as well as for its sociopolitical dimensions. We discover the healing power of dance in the views attributed to ancient Greek writers up to the early antiquity, in parallel with the historical -social, educational and political- uses of dance during that period (Homer, Plato, Aristotle, Xenophon, Plotinus, Athenaeus, Lucian, Plutarch, Nonnus and Libanius). The fact that the dances were of religious nature and had social functions (therapeutic, political and educational), or philosophical connotations, may be regarded as an essential element of their meaning and not as a restriction in applying a universal system of concepts in dance interpretation Nietzsche F, et al. [13].

To move on to the issue of dance and the way we are called today to understand it, as a vehicle for overcoming fear following the example of Eumenides [14,15], we will refer to Friedrich Nietzsche's philosophy of tragedy, since Nietzsche insists on the central role of the choral performance and its emotional impact on participants. Thanks to his emphasis on tragedy as a theatrical form of art and its effective function [16], as reflected in the song and the dance, Nietzsche appears as a forerunner of major contemporary trends in the philosophical critique of tragedy.

The aesthetic-therapeutic uses of modern dance/theater can be examined and philosophically justified as overcoming the pain of human condition through the art of dance -starting with the Nietzschean approach of the Dionysian. This perspective is mainly found in the Birth of Tragedy, while in Nietzsche's attitude towards art and its metaphysicalontological dimension a series of philosophical references to dance, ancient drama and art in general can also be located $[17,18]$ : Through the conception of an 'artistically defined metaphysics' Nietszche of the Birth of Tragedy captures the concept of man as a means for self-creation. Thus, man as an artist-creator appears to be both an implementer and a spectator of a process intrinsic to one's very existence and at the same time- greater than and beyond oneself [20-22].

Recently, there is a discussion about revival or in other words- reconstruction of ancient tragic choruses and dances with the help of technological and scientific possibilities and with the purpose of aesthetic crystallization on theatrical stage -or virtual reality [23], of research about ancient forms of dance as an attempt to capture linguistically and 
illustratively, the rhythmic and musical processes that took place far in the past, all the way expressing by means of movements and gestures, but also with vocal sound, emotions and thoughts of ancient people. Is this project 'therapeutic' of our contemporary world and individual lives? Can we face the horror of humanity in contemporary society with the therapeutic vehicle of tragic dance, reviving in the orchestra or in an educational dance procedure [24], so that we lead ourselves towards a new transcendence of negativity and fear? In another sense, following the historical heritage of an Isadora Duncan or an Eva Palmer of the $20^{\text {th }}$ century, may we recognize in modern dance revival of antiquity the medical -literally and metaphorically- uses and applications of ancient dance and drama?.

These questions, also taking under consideration the great educational and philological/linguistic applications of the studies in orchesis and ancient drama, today, lead to specifying the beneficial effects of such studies to the fields of translation and adaptation of classical dramas, offering more liberties by applying to the suffering, thinking, liberating therefore dancing body- of the contemporary man [25,26].

The aesthetic directions and criteria in today's revival of ancient cultural forms can be given now a moral meaning, 'therapeutic' in the broad sense, relevant with the needs of the modern man and even beyond scientific fidelity. It can be seen as a part of the self-analytical, self-aware and selfhealing of the human being that penetrates into the collective unconscious in order to dig out the forgotten sources of the vital part of the soul and remember the everlasting harmony of the dream world of a unifying identity with the whole. In view of certain contemporary developments in the fields of the performing arts, the identification of the body with its somatosensory sensibility [26], the discovery of the semioticphenomenological body, the methodological significance of 'embodiment' for the understanding of ancient art and the liberation of the artist from the unique meaning and the textcentered interpretation, I propose to 'move away' of the idea of the learning brain and 'approach' the idea of the learning dancing body, where the body (sense mind) is that entity that thinks and remembers, by playing and representing, speaking, translating and contemplating.

After all, it is good to remember that Sophocles, one of the three ancient Greek tragedians whose plays have survived, renown as the great innovator of ancient drama [25], was himself a poet, dancer and musician of the highest quality, at the same time, a reality that might use as a justification for attempting an all including orchestic interpretation of the famous stasimon on Eros by means of music, words AND dance- as therapy and education of the people.

\section{References}

1. Lazou A (2019) The athletic art of the orchestra \& the ancient physicality: an experience of self-knowledge \& transcendence for the modern man (The Athletic Art of Orchesis \& Ancient Physicality: an Experience of Self Awareness \& Transcendence of the Contemporary Man), Interpreting the ancient Greek dance (Interpretin the Ancient Greek Dance), Athens: 85-96.

2. Shanks M (1995) Art and Archaeology of Embodiment, Cambridge Archaeological Journal 5(2): 207-244.

3. John-Steiner V (2000) Creative Collaboration, Oxford University Press, Oxford UK.

4. Davis S (2015) Dramatic Interactions in Education: Vygotskian and Sociocultural Approaches, Bloomsbury Publishing.

5. Boal A (1995) The Rainbow of Desire. The Boal Method of Theatre and Therapy.

6. Leontyev AN (1997) On Vygotsky's Creative Development, In: Rieber RW, Wollock J, et al. (Eds.), The Collected Works of LS Vygotsky: Problems of the Theory and History of Psychology, Springer 3: 9-32.

7. Boal Kontopodis M (2011) Children, Development and Education: Cultural, Historical, Anthropological Perspectives. International Perspectives on Early Childhood Education and Development, Springer.

8. Blunden A (2009) 'Foreword' to Georg Wilhelm Friedrich Hegel, Hegel's Logic: Being Part One of the Encyclopaedia of the Philosophical Sciences, Marxists Internet Archive Publications.

9. (1987) Thinking and Speech, Collected Works of L.S. Vygotsky, Plenum Press, New York 1: 39-285.

10. Pellegrinis T (2002) Philosophy exercises for life and art, Greek Letters, Athens.

11. (2009) Psychological events and the body: The case of the actor on stage action (Mental events and the body: the Case of the Acting on Stage), Theatrographies 15: 2433.

12. Lazou A (2000) Therapeutic Justice (Justice as TherapyJustice for Therapy), Aristotle's Political Equality and Justice, In: Koutra D, et al. (Eds.), Aristotelian Studies Society. «The Lyceum» Athens: 285-297.

13. Nietzsche F (1872) Die Geburt der Tragodie aus dem Geiste der Musik, Leipzig. 
14. (2010a) An Interdisciplinary Theory of Activity, Studies in Critical Social Sciences, Brill 22.

15. (2010b) The Origins of Cultural Historical Activity Theory

16. Jornet A, Cole M (2018) Introduction to Symposium on Vygotsky and Spinoza. Mind, Culture, and Activity 25(4): 340-345.

17. Lazou I, Mastora A (2015) Fear-revenge-therapy: an anthropophilosophical approach to tragic dance in the example of the Eumenides (Fear-Revenge-Therapy: an Anthropo philosophical Approach of the Tragic Chorus in the Example of Eumenides), Orchesis \& Athletics, Arnaoutis books, Athens: 95-102.

18. Lazou A, Koszinski D, Krakow B (2001) The Functions of Ancient Greek Dance in a Philosophical Perspective (in Polish), Misteria, inicjacje (Mysteries and Initiations), pp: 87-96.

19. (2006) Apollonian and Dionysian Catharsis: On the diachronic aspect of ancient Greek dance culture, Abstracts of the $20^{\text {th }}$ World Congress on Dance Research, Athens.
20. (2013) Beyond Dance: Contemporary Aesthetic therapeutic Uses of Dance in the Light of Nietzsche's Thought, Journal Philosophein, Thessaloniki 8.

21. Lazou Mastora A(2015) Beyond Dance: The Philosophical Perspective in Investigating Ancient Greek Dance. A Hermeneutic vs. An Analytical Approach, Orchesis \& Athletics, Arnaoutis books, Athens: 83-91.

22. Kosma AL (2017) The Ancient Greek Drama in the Light of Orchesis, International Colloque of Theatre Translation (Teatro e traducao de Teatro), Belo Horizonte Minas Gerais University Publication.

23. Leontyev AN (1997) On Vygotsky's Creative Development, In: Rieber RW, Wollock J, et al. (Eds.), The Collected Works of LS Vygotsky: Problems of the Theory and History of Psychology, Springer 3: 9-32.

24. (2008) Philosophy on stage, Greek Letters, Athens.

25. Peponi AE (2013) Theorizing the Chorus in Greece, In: Billings J, Budelmann F, Makintosh F, et al. (Eds.), Choruses, Ancient and Modern, OUP, Oxford.

26. Vygotsky LS (1978) Problems of Method, Mind in Society, Harvard University Press, Cambridge, MA. 